\title{
ENTRE SHARON STREET E ADAM SMITH: UMA ANÁLISE DA INFLUÊNCIA EVOLUTIVA SOB A MODULAÇÃO DO SENTIMENTO DE SIMPATIA
}

\section{BETWEEN SHARON STREET AND ADAM SMITH: AN ANALYSIS OF THE EVOLUCIONARY INFLUENCE UNDER THE MODULATION OF THE FEELING OF SYMPATHY}

\author{
Thaís Alves Costa \\ Recebido: 05/2019 \\ Aprovado: 11/2019
}

\begin{abstract}
Resumo: Considerando o ponto arquimediano entre política, economia e moral na tríade de Adam Smith, a simpatia será analisada a partir de sua possível natureza biológica evolucionista e implicações metaéticas. Pautada nessa investigação, buscaremos propor em que medida esse sentimento poderá oferecer alternativas que amenizem problemas contemporâneos globais, tais como: crises econômicas, guerras e intolerância. Para isso, utilizaremos como fios condutores as obras: Teoria dos Sentimentos Morais e Riqueza das Nações de Adam Smith, A darwinian dilemma for realist theories of value de Sharon Street e $O$ acaso e a Necessidade de Jacques Monod.
\end{abstract}

Palavras-Chave: Simpatia, evolução, moral, sentimento.

\begin{abstract}
Considered the Archimedean point among politics, economics and morality in Adam Smith's triad, sympathy will be analyzed from its possible evolutionary biological nature and metaethical implications. Based on this research, we will seek to propose to what extent this feeling may offer alternatives to solve global contemporary problems, such as: economic crises, wars and intolerance. For this, I will use the following works: Teoria dos Sentimentos Morais e Riqueza das Nações of Adam Smith, A darwinian dilemma for realist theories of value of Sharon Street, and $O$ acaso e a Necessidade of Jacques Monod.
\end{abstract}

Keywords: Sympathy, evolution, moral, sentiments.

\section{Considerações iniciais}

Para compreendermos adequadamente o pensamento de Adam Smith, devemos partir da hipótese de que seu pensamento necessariamente deve ser entendido como uma teoria tripartite em um estreito equilíbrio entre economia, política e moral. Para isso, deve ser analisado

\footnotetext{
${ }^{1}$ Doutoranda do programa de pós-graduação em filosofia da Universidade Federal de Pelotas (UFPel), bolsista CAPES e mestranda do Programa de pós-graduação em Direito e Justiça Social da Universidade Federal de Rio Grande (FURG). E-mail de contato: costa.thaisalves@gmail.com
} 
conjuntamente as suas obras Riqueza das Nações (1776) e Teoria dos Sentimentos Morais (1759), o que permitirá entender como o corpus filosófico smithiano possui no sentimento de simpatia $^{2}$ a intersecção das três esferas de seu pensamento.

Na dimensão moral, a simpatia será entendida como uma espécie de "conexão orgânica" entre as pessoas, visto que proporciona ao individuo colocar-se no lugar do outro lançando mão do dispositivo da imaginação. Por meio desse movimento, será possível sentir, em certa medida, como aquele se sente, permitindo o autoconhecimento e o reconhecimento do outro como um igual. Conforme Smith, a simpatia será desenvolvida ao longo da experiência, sendo florescida através do hábito, ou seja, há uma relação necessária com a sua continuidade.

Do ponto de vista econômico, precisamos ter em mente que um dos pontos fundamentais da teoria smithiana é o entendimento de que o autointeresse não pode ser considerado o único sentimento que move as relações interpessoais na economia ${ }^{3}$, posto que há, antes de tudo, o sentimento de confiança recíproca "quando as pessoas de qualquer país têm tanta crença recíproca que assegura o funcionamento da economia"4. Por sua vez, a confiança é oriunda do sentimento de simpatia mútua, que é condição para as relações comerciais e o progresso econômico.

Por fim, a dimensão política prima por sociedades virtuosas e para isso, requer sujeitos cooperativos $^{5}$ e comportamentos justos. A necessidade da simpatia se dará, nessa esfera, com vistas à promoção do reconhecimento do outro o que gera indivíduos moralmente engajados em cooperar. Por sua vez, a simpatia deve ser ensinada e suscitada tanto em casa quanto pelas instituições educacionais. E, para isso, caberia pela ótica smithiana, lançar mão da intervenção

\footnotetext{
${ }^{2}$ Para sermos o mais possível ao conceito de Adam Smith (sympathy) utilizaremos sempre a palavra "simpatia". Entretanto, precisamos ressaltar que, contemporaneamente, essa ideia estaria mais próxima do que conhecemos como empatia do que da definição de simpatia. Confira: Stocker, (2009) Adam Smith, the City, Natural Order, Republicanism.

${ }^{3}$ De acordo com Sen: "Even as Smith's pioneering investigations explained why (and particularly how) the dynamism of the market economy worked, they also brought out the support that the markets need from other institutions for efficacy and viability. He identified why the markets may need restraint, correction, and supplementation through other institutions for preventing instability, inequity, and poverty". (SEN, 2009b, p. 53). ${ }^{4}$ SMITH, apud, SEN, 2009b, p. 55. Disponível em: <http://www.nybooks.com/articles/2009/03/26/capitalismbeyond-the-crisis/>. Portanto, a motivação para as trocas comerciais não é uma defesa da mera busca por obtenção de vantagens individuais que estaria atrelada a teoria da escolha racional, consistindo apenas na promoção do autointeresse. Tal dedução extraída de sua teoria provém da interpretação tout court e equivocada da frase, "não é da bondade do homem do talho, do cervejeiro ou do padeiro que podemos esperar o nosso jantar, mas da consideração em que eles têm o seu próprio interesse." (SMITH, 1776, p.30). O que esta passagem indica é como se dão as operações comerciais, ou seja, apenas que negociações com vantagens mútuas são comuns e não que somente o autointeresse regeria a economia, sendo o suficiente para uma sociedade progredir. Ademais, se fizermos um estudo atento da palavra utilizada por Smith encontraremos o termo exchange em detrimento de distribuição ou produção, demonstrando que a sua proposta é de um intercâmbio sustentável, no qual deve predominar a autoconfiança e não a simples obtenção de vantagem.

${ }^{5}$ Confira o capítulo Of the pleasure of mutual Sympathy de Teoria dos Sentimentos Morais de Adam Smith.
} 
do Estado para que todos possam ter educação, sinalizando um viés de justiça social distributiva.

Considerando o papel chave da simpatia no pensamento smithiano, analisar o seu locus oferecerá diferentes implicações de metaética evolucionista que fomentarão desdobramentos diversificados. Para isso, inicialmente, iremos analisar o que é o sentimento de simpatia em Adam Smith e, em seguida, averiguaremos a sua possível origem na natureza. Posteriormente, estabeleceremos as possíveis implicações morais das perspectivas originárias apresentadas. Por fim, concluiremos tentando responder em que medida a simpatia de Smith contribuiria para a amenização de problemas contemporâneos, tais como crise econômica, intolerância e guerra.

\section{Sympathy: o móbil das ações humanas em smith}

Segundo Smith, toda e qualquer experiência sobre as quais são fundamentadas as regras gerais do comportamento humano são antes de tudo, objetos originados dos sentidos e sentimentos imediatos e não da razão. Por isso, Smith é um sentimentalista e não um racionalista para a moral. Partindo disso, a "simpatia" é entendida como um conceito que surge a partir da análise de sentimentos reais, isto é, do modo como as pessoas, com suas experiências na vida em sociedade incorporam os diferentes sentidos de moralidade de forma coordenada e cooperativa. Como ele mesmo afirma em Teoria dos Sentimentos Morais:

\footnotetext{
Por mais egoísta que se suponha o homem, evidentemente há alguns princípios de sua natureza que o fazem interessar-se pela sorte dos outros, e considerar a felicidade deles necessárias para si mesmo, embora nada extraia disso senão o prazer de assistir a ela (...). É fato obvio demais para precisar ser comprovado, que frequentemente ficamos tristes com a tristeza alheia, pois esse sentimento, como todas as outras paixões originais da natureza humana, de modo algum se limita aos virtuosos e humanitários, embora esses talvez a sintam com uma sensibilidade mais delicada. O maior rufião, o mais empedernido infrator das leis da sociedade não é totalmente desprovido desse sentimento (SMITH, 1759, p. 05).
}

Nesse sentido, a simpatia poderá ser entendida de duas formas. Por um lado, ela pode ser passível e mecânica, consistindo na reação imediata a um determinado estímulo. Como exemplo, podemos imaginar quando alguém é recebido com um largo sorriso pelo atendente da lanchonete da universidade e, automaticamente, sente-se impulsionado a corresponder também com um sorriso. Tal fenômenos ocorre pois, "dor e alegria intensamente expressas no olhar ou gestos de qualquer pessoa, imediatamente afetam o espectador com uma semelhante emoção 
dolorosa ou agradável"'(SMITH, 1759, p. 08). Esse movimento mecânico de um rosto alegre nos fazer feliz e um triste nos angustiar, acarreta que sintamos automaticamente confiantes em relação ao outro através de gestos simples como o olhar franco e o aperto de mão forte. De acordo com Smith,

Quando vemos que um golpe está prestes a ser desferido sobre a perna ou braço de outra pessoa naturalmente encolhemos e retiramos nossa própria perna ou braço; e , quando o golpe finalmente é desferido, de algum modo o sentimos e somos por ele tão atingidos quanto quem de fato o sofreu. Ao admirar um bailarino na corda bamba, as pessoas da multidão naturalmente contorcem, meneiam e balançam seus corpos como o vêem fazer, e como sentem que teriam de fazer se estivessem na mesma situação. (SMITH, 1759, p. 06).

Por outro, a simpatia também pode ser sentida como algo sensível e direcionado, ocorrendo quando nos colocamos no lugar do outro. A partir dessa disposição conseguimos entender a situação pela qual a pessoa está passando. Ao ver que uma pessoa está triste, não me sinto automaticamente no lugar dela, a não ser que eu entenda a situação em que ela está passando. Por exemplo, se esta pessoa está triste por ter perdido um ente querido. Essa situação é muito mais forte e abrangente que a primeira e nos permite colocarmo-nos na posição alheia.

Imagine a seguinte situação. Carla é uma balzaquiana que odeia crianças e nunca se imaginou sendo mãe. Durante uma viagem de ônibus, senta ao lado dela, uma mulher lamentosa da vida, pois acabara de perder o seu único filho. Apesar de Carla nunca ter sequer imaginado tendo filhos, ainda assim, sente pela dor daquela mãe. Carla nunca poderá sentir exatamente aquela dor materna, uma vez que esse é exclusividade de quem sente. Entretanto, mesmo diante de todas as circunstâncias, Carla simpatiza-se com aquela dor.

Mesmo que eu lamente a dor do outro, esta pertence à pessoa, haja vista que há uma barreira epistemológica entre nós. Diante dessa realidade, o simpatizar-se ocorre a partir do sentimento formado pela ideia sobre o que ocorre numa dada situação. O único modo pelo qual podemos formar essa ideia é, supondo-nos em circunstâncias idênticas, imaginar como reagiríamos nesses casos. Entretanto, é impossível concedermo-nos colocados em qualquer situação, agradáveis ou não, sem sentirmos um efeito semelhante ao que a própria situação em nós mesmos produziria. Consequentemente, a atenção que damos, num certo momento, às circunstâncias de outrem deve nos afetar de modo semelhante, embora jamais com a mesma intensidade com que seríamos afetados se nós mesmos estivéssemos em tais. Isso ocorre porque “nossa imaginação imita a impressão de nossos próprios sentidos”. (SMITH, 1759, p. 08). Será 
através do dispositivo da imaginação que conseguiremos nos colocar no lugar do outro e nessa projeção iremos nos conectar a aquele. Nesse sentido, para Smith, em todas as paixões de que é suscetível o espírito humano, as emoções do observador, ao colocar-se nas mesmas circunstancias, sempre corresponderão aos sentimentos que imagina seriam os de quem sofre.

Para Smith, o "simpatizar" se relaciona, literalmente, com o compartilhar de sentimentos (fellow-feelings) entre indivíduos socializados. Tal sentimento será moldado, em larga medida, pelos sentimentos de terceiros que sobre mim recaem. Esta "transposição de corpos" influencia os sentimentos, na medida em que possui uma clara derivação reflexiva, haja vista que, se sou capaz de sentir, em algum nível, a dor alheia, também sou capaz de, colocandome uma vez mais no lugar do outro, investigar o que ele sente a respeito de minha própria dor. Há aqui dois movimentos distintos, o sentimento do outro que em mim aporta (reconhecimento), e o meu sentimento, que a mim retorna (conhecimento), mas transmutado pela visão do outro. A simpatia, nessa medida, não é apenas sentir o que o outro sente, mas também sentir o que sentiríamos se fôssemos o outro. Reconheço o outro como igual a mim, e me conheço na imagem que vejo de mim no outro.

\section{O locus da simpatia}

A compreensão da natureza do sentimentalismo ${ }^{6}$ simpático smithiano poderá oferecer subsídios biológicos para a defesa de sua tríade, para esse feito, analisaremos os posicionamentos e implicações de três teorias evolucionistas clássicas, a saber: A. perspectiva gênica; B. seleção natural; C. interação cultural. Cada corrente engendrará diferentes desdobramentos morais e práticos, como veremos a seguir.

De acordo com a Perspectiva Gênica Clássica (A), a base genética é a responsável por estabelecer as disposições comportamentais do agente. Pautando-se no conceito molecular clássico, o gene é o segmento do DNA que codifica uma determinada função no sistema biológico $^{7}$. Em outras palavras, é como uma unidade física e funcional fundamental da

\footnotetext{
${ }^{6}$ Cf. Stanford Encyclopedia em: <https://plato.stanford.edu/entries/morality-biology/>.

${ }^{7}$ Entretanto, apesar da força com que essas correntes clássicas defenderam suas ideias, recentemente, teorias evolutivas tendem a considerar todos esses elementos e outros mais em conjunto, sendo totalmente insuficiente a explicação reduzida a qualquer uma dessas perspectivas. Contemporaneamente, Portin afirma que nosso conhecimento da estrutura e função do material genético ultrapassou a terminologia usada para descrevê-lo e que pode ser que o termo "gene" esteja insuficiente para a explicação dos fenômenos da natureza. (Cf. PORTIN, 1993, p. 173). Keller, por exemplo, escreve que o gene é um conceito problemático e sugere que chegou o tempo de forjar novas palavras e deixar esse conceito de lado. (KELLER, 2005, p. 101). Outros autores, menos céticos, propõem que é preciso salvar o conceito de gene através de uma redefinição que não incorpore simplesmente a
} 
hereditariedade, na qual, a sequência ordenada de nucleotídeos localizada em uma posição específica codifica um produto funcional particular, determinando as características estruturais e funcionais de maneira inata ${ }^{8}$. Partindo dessa corrente de pensamento, o comportamento humano estaria determinado de antemão com base na sua genética. Nesse sentido, os níveis de simpatia seriam pré-determinados geneticamente, o que poderia tornar a possibilidade de ensino e promoção da simpatia algo irrelevante.

Com o intuito de endossar tal posição, Hatfields realizou estudos que objetivavam mensurar os níveis de simpatia e sua relação com possíveis disposições genéticas dos agentes. Para a realização dos testes foi estabelecido um "traço quantitativo" ${ }^{9}$ no qual era possível relacionar estatisticamente o desempenho de cada participante com o seu genoma. Por meio dessa relação, verificou-se que a maior parte das pessoas envolvidas possuíam níveis médios de simpatia, o que para ele, era considerado saudável em termos sociais e psicológicos. Todavia, alguns foram detectados com níveis extremados, o que estava diretamente associado a patologias como, em baixo nível, autismo e a psicopatia ${ }^{10}$ e alto nível a Síndrome de Williams ${ }^{11}$.

Em contrapartida, esse ano foi divulgado os resultados do maior estudo genético acerca da simpatia, envolvendo mais de 46.000 pessoas. Liderada por Vurun Warrier e Simon BaronCohen (ambos da University of Cambridge), Thomas Bourgeron (Université Paris Diderot) e David Hinds (23andMe Company) a pesquisa investigou, através de amostras de saliva e questionários, o coeficiente de simpatia (tanto a afetividade quanto o dispositivo de se colocar no lugar do outro). Após a minuciosa observação de 10 milhões de variantes genéticas, foi descoberto que essas contribuem coletivamente para cerca de $10 \%$ das diferenças de níveis de

ideia de genes como unidades básicas da matéria viva (cf. Fogle (1990), Are genes units of inherance?, p. 349). O genoma, por sua vez, passa a ser tratado como parte do sistema celular, que "constrói, define e usa o genoma como parte do seu mecanismo de memória, como um banco de dados interativo" (GUIMARÃES; MOREIRA, 2000, p. 249).

8 Cf. Venter (2001) texto The sequence of the human genome e http://www.ornl.gov/sci/techresources/Human_Genome/glossary/glossary_g.shtml.

${ }^{9}$ Para Alexandre Rosenberg na obra Darwinism Reductionism, a estipulação de um traço genético para determinar o comportamento humano terá que lidar com dois grandes problemas: "1. Most traits of interest are hard to operationalize, so that individuals who instantiate them to the greatest degree are hard to identify; in effect, the traits of interest are not themselves phenotypes, but at most packages of phenotypes or the result of phenotypic and environmental interaction. 2. At best, QTL studies will identify a set of loci - perhaps ten or more relatively large stretches of DNA - that are jointly highly correlated with the instantiation of a high degree of some quantitative trait in a "normal environmental range." Nothing will be revealed by such studies about the biosynthetic pathways from these genes to the actual behavior they are supposed to be the "genes for." It is easy to see how these problems will bedevil the attempt to employ genomics as evidence to test alternative theories about how human cooperation emerged.(ROSENBERG, 2006, p. 209).

${ }^{10}$ Nesse caso há um fator latente com heritabilidade estimada de $\mathrm{h}=0,63$, que é considerado elevado.

${ }^{11}$ Uma perturbação de ordem genética nas deleções no cromossomo 7, em que os indivíduos, excessivamente empáticos, são incapazes de deixarem de se perturbar intensamente com as experiências emocionais dos outros. 
simpatia. Esse resultado demonstrou que, se por um lado a nossa simpatia se deve, em parte, à genética, por outro, a variação percentual representou apenas um décimo no todo da formação do comportamento humano para a simpatia, o que não parece ser suficiente para o desenvolvimento desse sentimento de per si.

Por outro lado, a teoria evolucionista da Seleção Natural Clássica $(B)$, pode ser descrita como uma força ou processo de origem populacional ${ }^{12}$, que consiste na "existência de variação em alguma característica nos indivíduos de uma população, ou seja, variabilidade intraespecífica (...). O crivo seletivo ocorreria em um ambiente de competição em que o resultado é a distribuição genotípica da população". (SANTILLI, 2011, p. 194). Partindo dessa ótica, a seleção natural defenderá que, surgindo como um mecanismo evolutivo de adaptação, a simpatia é motivada pelo autointeresse. Nesse sentido, a cooperação ocorre egoisticamente com vistas à sobrevivência da prole. Aprendida via imitação, o sentimento de simpatia será, com o tempo, registrado na memória ${ }^{13}$. Para demonstrar essa posição, Preston e Waal propuseram o modelo da Boneca Russa ${ }^{14}$ para vincular o desenvolvimento do processo simpático via imitação, estabelecendo como a reprodução espontânea de novos atos foi capaz de produzir inputs sensoriais díspares quando observados e executados desenvolvendo a simpatia.

Para eles, a simpatia e a imitação compartilham da mesma estrutura motivacional, por isso envolvem similarmente as representações compartilhadas, identificação por similaridade física, automaticidade e espontaneidade. Essas representações compartilhadas são facilmente encontradas na natureza. Por exemplo, há indícios de que os Chimpanzés já imitavam atos como os de bocejar, coçar e a visão de outros que comem. Filhotes de macacos já imitavam expressões faciais assim como os bebês humanos fazem. Tais imitações propiciam a criação e transmissão dessa simpatia mecânica que já fora tratada por Smith como simpatia de caráter imediato e

\footnotetext{
${ }^{12}$ Ao tratar de seleção natural, George Willimas no livro Adaptation and Natural Selection(1960) argumentou que os genes são o principal foco da seleção, dando pouco valor para questões comportamentais. Segundo ele: "um gene é um pacote de informações, não um objeto. O padrão dos pares de bases na molécula de DNA especifíca o gene. Mas a molécula de DNA é o meio, não a mensagem. Manter essa distinção entre o meio e a mensagem é absolutamente indispensável. Para se ter clareza de pensamento quando se trata de evolução". (WILLIAMS, 1960, p. 99). Assim, associou seleção natural com a genética.

${ }^{13}$ Kitcher argumenta que "os hominídeos com a tendência de agir de acordo com as disposições altruístas teriam se saído melhor do que os que não o possuíam", pois isso lhes daria um acesso mais fácil a "coalizões vantajosas" (STREET, 2006, p. 172). Ele sugere, além disso, que uma capacidade evoluída de governança normativa teria permitido que nossos ancestrais desenvolvessem uma "protolocalidade" que reforçaria tais disposições e seria transmitida por gerações. Monod também dirá que a reunião dos grupos foi somente em prol da sobrevivência, pois a evolução humana tende a favorecer aqueles que são corajosos em grupo do que os corajosos solitários.

${ }^{14}$ Confira: PRESTON; WAAL, 2002, p. 02, George Williams - Adaptation and natural selection (1960) e Bard (2007). Neonatal imitation in chimpanzees (Pan troglodytes) tested with two paradigms.
} 
espontâneo ${ }^{15}$.

Por fim, a interação Cultural (C) endossa que a simpatia é originada das variantes culturais elaboradas a partir de padrões de comportamento, representados cognitivamente e transmitidos de geração em geração. Nesse caso, a cultura consiste na manifestação do conjunto de fenômenos materiais e ideológicos que caracterizam um grupo étnico, ou seja, uma civilização com linguagem, gestos e vestimentas que manifestam suas experiências. Os comportamentos, nessa visão, funcionariam como categorias simbólicas, convertendo-se em crenças particulares que, ao serem transmitidas ao longo do tempo, garantem a acumulação de técnicas, conhecimentos e estratégias organizativas ${ }^{16}$. Assim, a simpatia seria desenvolvida através das interações culturais e sua motivação não teria como base o autointeresse, mas a cooperação ${ }^{17}$.

\section{Qual relação de tudo isso com a moral?}

Considerando a biologia evolutiva e sua influencia na modulação do comportamento humano, como nas perspectivas clássicas apresentadas no tópico anterior, faz-se necessário problematizar como as forças evolutivas interferiram no nosso comportamento ao ponto de considerarmos a simpatia como um sentimento bom. Em outras palavras, a pressão evolutiva teria o poder de influenciar o que consideramos certo ou errado? Poderíamos considerá-la como uma herança totalmente genética a ponto de transmitir genes perfeitamente análogos de tal forma que o correto seria uma aptidão inata, devendo apenas ser revelado? Ou aquilo que consideramos certo ou errado está em contínua construção, sendo moldado "através do longo curso evolutivo" (RICHERSON; BOYD, 2005, p. 4)? Na tentativa de encontrar respostas satisfatórias, lançaremos mão da premissa empírica de Sharon Street apresentada no texto $A$ darwinian dilemma for realist theories of value. Segundo ela,

Em particular, podemos esperar que tenha havido uma pressão esmagadora no sentido de fazer essas avaliações avaliativas que tendiam a promover o sucesso reprodutivo (como o julgamento que a vida é valiosa), e contra fazer aqueles julgamentos avaliativos que tendiam a diminuir o sucesso reprodutivo (tal como o julgamento de que deveríamos atacar a nossa prole). (STREET, 2006, p. 114).

\footnotetext{
${ }^{15}$ A relação entre observação e imitação é apoiada por dados neurofisiológicos em relação ao comportamento facial emocional: tanto um quanto o outro é ativado pelo mesmo grupo de estruturas cerebrais, incluindo o córtex pré-motor aórtico, a ínsula e a amígdala, como observado por Waal.

${ }^{16}$ Cf. BARAVALLE, 2014, p. 126.

${ }^{17}$ Está proposta está baseada no aquaintance, isto é, no hábito.
} 
Nesse sentido, ao partirmos da metaética evolucionista e da crença de que os nossos julgamentos evolutivos foram influenciados pela pressão seletiva da teoria de Darwin, Sharon Street ${ }^{18}$ defenderá sua tese acerca de quão intensa poderia ter sido a influência da pressão evolutiva no nosso comportamento e o sentimento que consideramos ou não como correto. Por sua vez, determinar a intensidade da influência do elo evolutivo permitiria definir em que medida essas forças determinaram o porquê da simpatia ser correta. Para Street, há duas possibilidades das forças evolutivas terem influenciado a forma com que lidamos com a moral e, em consequência, com a simpatia.

A primeira alternativa consiste na defesa de que "os padrões observados no conteúdo real dos julgamentos avaliativos fornecem evidencias em favor da visão de que a seleção teve uma tremenda influência nesse conteúdo". (STREET, 2006, p.117) ${ }^{19}$. Nesse sentido, as forças evolutivas teriam influenciado diretamente nossos juízos morais, determinando o conteúdo das nossas avaliações. Nessa formulação, o certo ou o errado que é rastreado pelo sentimento de simpatia, já teria o seu conteúdo determinado pela pressão evolutiva. Entretanto, considerar a simpatia como determinada anteriormente pela força evolutiva significa dizer que ela é inata ${ }^{20}$, implicando em diversos problemas. Por exemplo, se adotarmos o reducionismo genético, enfrentaremos controvérsias como a desconsideração dos traços adquiridos ao longo da vivência, como ocorre com gêmeos idênticos que não desenvolvem o mesmo nível de simpatia em circunstâncias iguais, bem como a desconsideração de traços congênitos que também são inatos.

Ao passo que na segunda hipótese, as forças evolutivas teriam moldado apenas os traços

\footnotetext{
${ }^{18}$ Sharon Street apresenta uma resposta para o dilema darwiniano que parte da hipótese de Darwin, segunda a qual as tendências para ter certos tipos de respostas avaliativas, em vez de outras, promovem o sucesso reprodutivo entre nossos ancestrais porque elas forjaram elos adaptativos entre as circunstâncias de nossos ancestrais e suas respostas a essas circunstâncias, levando-os a agir, sentir e acreditar em maneiras que se revelaram reprodutivamente vantajosas.

${ }^{19}$ Outra evidência em prol dessa visão é a continuidade marcante com que observamos entre muitos dos nossos proprios juizos avaliativos mais básicos observados igualmente em outros animais, especialmente aqueles mais proximos a nós.

${ }^{20}$ Fazendo analogia ao revelado e criado de Monod em Chance and Necessity. Sobre esses conceitos e suas distinções Monod afirma: "the idea of "revelation" applies to epigenetic development, but not of course to evolutionary emergence, which, owing precisel to the fact that it arises from the essentially unforeseeable, is the creator of absolute newness"(MONOD, 1970, p.116.). Monod irá frisar o caráter espontâneo do processo de epigênese molecular, salientando que individualmente as moléculas são desprovidas de suas atividades e propriedades funcionais, mas quando se organizam, elas se revelam. A informação estava presente, em potencial, apenas inexpremida. Diante disso, toda estrutura primária de proteína nos aparece como o puro produto de uma escolha feita ao acaso, e num outro sentido, a sequência de cada proteína de forma alguma foi sintetizada ao acaso, pois a mesma ordem é reproduzida, praticamente sem erro, em todas as moléculas da proteína considerada, milhões de vezes, em cada organismo e a cada geração. Assim, o acaso é reproduzido com invariância e convertido numa necessidade.
} 
psicológicos de nosso caráter, e não o seu conteúdo. Em outras palavras, a pressão evolutiva teria influenciado os nossos juízos avaliativos de modo indireto, apenas no que tange à nossa estrutura psicológica, ou seja, como elaboramos os juízos morais e não seu conteúdo avaliativo. Nessa medida, a simpatia seria um sentimento construído ao longo do tempo e a força evolutiva apenas teria desempenhado o papel de moldar a arquitetura de como pensamos, ou seja, seu poder é ser "especializado em assimilar, armazenar e utilizar informações culturais" (LALAND; BROWN, 2002, p. 243). Como no caso da seleção natural e da interação cultural. Sharon Street irá endossar essa segunda perspectiva, haja vista que, para ela, as forças evolutivas influenciaram tremendamente (tremensdously) os nossos juízos avaliativos, porém indiretamente. Como resultado, nosso sistema moral está impregnado de influência evolutiva, entretanto não de forma determinante.

Escolher dentre uma ou outra hipótese provoca visões contrapostas. Caso a influência seja indireta e a pressão evolutiva moldou somente a nossa estrutura psicológica, segundo a qual eu consigo ajuizar que o altruísmo é correto e o egoísmo incorreto, ela possui uma natureza construída. Em termos estruturais ela apenas nos ajudaria a determinar o que é certo e o que é errado. Por outro lado, considerá-la como inatamente dada, ou seja, seu conteúdo, aquilo que consideramos certo ou errado já está determinado de antemão, a formação moral do agente é enfraquecida. A simpatia, sob esse viés, existiria enquanto conteúdo dado, necessitando apenas ser revelada. Conforme Rosenberg:

it seems more reasonable to assume that cooperative behaviors are the results of the collaboration of a number of different behavioral dispositions all simply reinforced by their environments, that is, dispositions ontogenetically selected for, though not phylogenetically selected for. (ROSENBERG, 2006, p. 212).

Ao contrário das perspectivas clássicas, contemporaneamente, a compreensão evolucionista do sentimento de simpatia passou a reconhecer múltiplas perspectivas, tais como, genes, organismos, população, grupos, metagrupos, espécies e coletivos sociais ${ }^{21}$. Assim como ocorre com a cooperação, é insuficiente considerar o sentimento de simpatia com locus apenas em um único estamento biológico ${ }^{22}$, haja vista envolver outros elementos. Ademais, nos

\footnotetext{
${ }^{21}$ Outro ponto relevante para ressaltar as interações de diversos fenômenos na promoção e desenvolvimento da simpatia é a teoria da dupla herança de Richerson e Boyd (op cit), segundo a qual, as características atuais das espécies são resultado de uma construção genética e cultural. Encontraremos uma explicação dos comportamentos humanos, como a simpatia, através da transmissão de informações horizontais (entre indivíduos) e verticais (de gerações a gerações), nas quais os genes e o ambiente (adaptativo e cultural), moldam o nosso comportamento.

${ }^{22}$ Conforme Sober e Wilson: “As teorias [clássicas] que foram propostas como alternativa à seleção de grupo são simplesmente diferentes maneiras de ver a evolução em populações estruturadas em grupo. Esta não é uma
} 
valendo do conceito biológico de eneblement ${ }^{23}$, mesmo que todas as variáveis biológicas, psicológicas, ambientais, culturais e sociais sejam favoráveis para o desenvolvimento da simpatia, ela não será necessariamente desenvolvida, pois é apenas uma condição de possibilidade.

\section{Considerações finais}

O reconhecimento de que as forças evolutivas moldaram a nossa estrutura psicológica, influenciando a maneira com que realizamos julgamentos morais, permite aos agentes “discernir as consequências remotas de todos os nossos atos, e a prever o benefício ou prejuízo que provavelmente resultarão deles”. (SMITH, 1759, p. 189). Sendo assim, ao afirmar que a simpatia é construída ao longo da experiência e do hábito, devendo ser promovida tanto pela escola quanto em casa, Adam Smith parece concordar com Sharon Street acerca da relação entre a pressão evolutiva e os juízos morais.

Diante da influência engendrada pelo elo evolutivo, o sujeito smithiano aparenta estar constantemente frente a um jogo de espelhos que reflete o exercício da simpatia enquanto contínua mediadora dos relacionamentos sociais. Partindo disso, há uma constante necessidade de desenvolvimento desse sentimento. Por sua vez, as pessoas ao observarem os comportamentos e as reações a certos tipos de ações e sentimentos dos outros, assimilam padrões de julgamento que fazem com que o exercício de captar os sentimentos alheios possibilite tanto apreender os padrões morais como aplicá-los. Dada a diversidade de aspectos envolvidos no locus da simpatia, a educação, uma vez mais se torna necessária para uma nação próspera.

Por meio da simpatia, somos capazes de oferecer alternativas que podem amenizar problemas contemporâneos, tais como: crise econômica, intolerância, desrespeito e conflitos civis e internacionais. Basta considerar que, as crises econômicas, muitas das vezes são

interpretação indiossincrática nossa, mas que está se impondo como um consenso entre os biólogos teóricos e outros que estão muito familizarizados com os fundamentos conceituais da biologia evolutiva. (SOBER; WILSON, 1998 p. 98). Partindo disso, diversos biólogos e filósofos buscaram, atraves do elo evolutivo, traçar estágios de desenvolvimento do comportamento humano considerando aspectos fisiológicos (mecânicos), de ontogênese (desenvolvimento), sobrevivência e filogênese (evolução).

${ }^{23}$ Condição de ter, mas não há essa necessária correspondência. Em outras palavras, o fenômeno da simpatia não pode possuir uma causalidade necessária. Por tudo isso, abrimos uma porta sem fecharmos as outras. Apenas, defendemos que matematicamente, há uma fragilidade, pois o fato de um fenômeno ser mais provável que outro não implica em sua necessária causalidade. São apenas condições favoráveis, não obstante, não possuímos a probabilidade dos possíveis. Por outro lado, esse conceito biológico permite que o novo elemento venha trazer uma nova situação. 
provenientes da falta de confiança entre as pessoas e entre países. Portanto, sendo a confiança oriunda da simpatia mútua, na medida em que ela passa a ser promovida, mais desenvolvida tornam-se as relações econômicas e, por consequência o desenvolvimento da nação. Este desdobramento permitirá tanto a melhoria de vida da população quanto a diminuição da pobreza. Em termos políticos, a vida em sociedade é mais harmoniosa quando há respeito recíproco.

Por tudo isso, a simpatia é o sentimento capaz de promover o autoconhecimento e o reconhecimento do outro como um igual a mim. Por sua vez, esse sentimento propiciará um convívio social com agentes solidários e livres de preconceitos. Ademais, a sensação de pertencimento à comunidade poderá florescer e, consequentemente, as pessoas sentirão mais motivadas a cooperarem e a adotarem comportamentos justos, o que é condição sine qua non para uma sociedade pacífica e próspera. Expondo sua urgência e atualidade, podemos concluir que se a tríade smithiana tivesse sido corretamente estudada, muitos dos nossos problemas atuais teriam sido evitados.

\section{Referências bibliográficas}

BARAVALLE, “As muitas faces do altruísmo: pressões seletivas e grupos humanos”. Scientice Studia. São Paulo, v. 12, n. 1, p. 97-120, 2014.

BARD, K. "Neonatal imitation in chimpanzees (Pan troglodytes) tested with two paradigms". Animal Cognition, 10, 233-242, 2007.

COSTA, T. A; BARBOSA, E. “A economia internacional como promotora do desenvolvimento humano a partir da releitura de Amartya Sen sobre a teoria de Adam Smith". Conjectura: Filosofia E Educação 23 (2), p. 402-418, 2018.

FOGLE, T. “Are genes units of inheritance?”. Biology and Philosophy, v.5, 1990.

GUIMARÃES; MOREIRA. "O conceito sistêmico de gene - uma década depois". Autoorganização: estudos interdisciplinares. Campinas: CLEUnicamp. v. 2, p. 248-80, 2000.

HUME, David. Treatise of Human Nature. Oxford: Oxford University Press, 2000.

. "Of the Standard of Taste". Essays, Moral, Political and Literary. Indianápolis:

Liberty Fund., p. 227-249, 1987.

HUTCHESON, F. "Uma investigação sobre o bem e o mal do ponto de vista da moral". Filosofia Moral Britânica: textos do século XVIII. Campinas: Ed. Unicamp, 1996.

An inquiry into the original of our ideas of beauty and virtue: in two treatises.

Indianapolis: Liberty Fund, 2004. 
KELLER, E. F. O século do gene. Belo Horizonte: Crisálida, 2002.

. "The century beyond the gene". Journal of Biosciences, 30, 1, p. 101-8, 2005.

LALAND, K.; BROWN. G. Sense and Nonsense: Evolutionary Perspectives on Human Behaviou. Oxford: Oxford University Press, 2002.

MONOD, J. Chance and Necessity. New York: Randon House, 1970.

MORROW, G."The significance of the sympathy in Hume and Adam Smith”. Philosophical Review, n. 32, 1924. Co., 1969.

The Ethical and Economic Theory of Adam Smith. Nova York: Longmans, Green and

PORTIN, P. "The concept of the gene: short history and present status". Quarterly Review of Biology, 56, p. 173-223, 1993.

PRESTON, S; WAAL, F. "Empathy: Its ultimate and proximate bases". Behavioral and brain sciences. 25, p. 1-72. 2002.

RICHERSON, P; BOYD, R. Non di soli geni. Come la cultura ha trasformato l'evoluzione umana. Torino: Codice Edizioni, 2006.

ROSENBERG, A. Darwinism in philosophy, social science and policy. Cambridge: Cambridge University Press, 2000.

Darwinian reductionism, or, How to stop worrying and love molecular Biology. Chicago: The University of Chicago Press, 2006.

Philosophy of biology: a contemporary instroduction. New York: Routledge, 2008.

SANTILLI, E. "Níveis e unidades de seleção: pluralismo e seus desafios filosóficos". Filosofia da Biologia. São Paulo: Editora Artmed, 2011.

SEN, Amartya. Adam Smith and the Contemporary World. Erasmus Journal for Philosophy and Economics, Volume 3, Issue 1, Spring, p. 50-67, 2010.

Adam Smith's market never stood alone, 2009a. Disponível em: https://www.ft.com/content/8f2829fa-0daf-11de-8ea3-0000779fd2ac. Acesso em 28 de novembro de 2018.

Capitalism Beyond the crisis, 2009b. Disponível em: http://www.nybooks.com/articles/2009/03/26/capitalism-beyond-the-crisis/. Acesso em $04 \mathrm{de}$ dezembro de 2018. . On ethics and economics. Oxford: Clarendon Press, 1987.

SMITH, Adam. An Inquiry into the Nature and causes of the wealth of nations. Chicago: The 
University of Chicago Press, 1776.

O Inquérito sobre a natureza e as causas da Riqueza das Nações. Lisboa: Fundação Calouste Gulbenkian, 2014.

. Teoria dos Sentimentos Morais. São Paulo: Wmf Martins Fontes, 1999.

. The theory of Moral Sentiments. Cambridge: Cambridge University Press, 1759.

SOBER, E.; WILSON, D. S. "El comportamiento altruísta”. Evolución y psicología, Madrid: Siglo Veintiuno, 2000.

STANFORD ENCYCLOPEDIA. 2018.2 Disponível em: https://plato.stanford.edu/entries/morality-biology/. Acesso em 11 de dezembro de 2018.

STOCKER. Adam Smith, the city, natural order, republicanism. Disponível em: <http://istanbulfactsandideas.blogspot.com.br/2009/08/adam-smith-city-natural-order.html >. Acesso em 25 de julho de 2018.

STREET, Sharon. "A darwinian dilemma for realist theories of value". Philosophical Studies V. 127 (1), p.109-166, 2006.

TAVORY, I.; GINSBURG, S.; JABLONKA, E. "The Reproduction of the Social”. Developing Scaffolds in Evolution, Culture, and Cognition. Cambridge: MIT Press Scholarship Online, 2013.

UNITED STATE OF AMERICA. Human Genoma Project Informatio Archive http://www.ornl.gov/sci/techresources/Human_Genome/glossary/glossary_g.shtml. Acesso em 01 de novembro de 2018.

VENTER. C. "The sequence of the human genome”. Science, 291, p. 1305-51, 2001.

WILLIAMS, G. Adaptation and Natural Selection: a critique of some current evolutionary thought. Princenton: Princenton University Press, 1966. 